\title{
Identification of an RNase J ortholog in Sulfolobus solfataricus: Implications for 5'-to-3' directional decay and $5^{\prime}$-end protection of mRNA in Crenarchaeota
}

\author{
DAVID HASENÖHRL, ${ }^{1}$ ROBERT KONRAT, ${ }^{2}$ and UDO BLÄSI ${ }^{1}$ \\ ${ }^{1}$ Max F. Perutz Laboratories, Department of Microbiology, Immunobiology and Genetics, University of Vienna, 1030 Vienna, Austria \\ ${ }^{2}$ Max F. Perutz Laboratories, Department of Biomolecular Structural Chemistry, University of Vienna, 1030 Vienna, Austria
}

\begin{abstract}
In both Bacteria and Eukaryotes, degradation is known to start at the $5^{\prime}$ and at the $3^{\prime}$ extremities of mRNAs. Until the recent discovery of $5^{\prime}$-to-3' exoribonucleases in hyperthermophilic Euryarchaeota, the exosome was assumed to be the key enzyme in mRNA degradation in Archaea. By means of zymogram assays and bioinformatics, we have identified a 5' -to-3' exoribonuclease activity in the crenarchaeum Sulfolobus solfataricus (Sso), which is affected by the phosphorylation state of the $5^{\prime}$-end of the mRNA. The protein comprises typical signature motifs of the $\beta$-CASP family of metallo- $\beta$-lactamases and was termed Sso-RNAse J. Thus, our study provides the first evidence for a 5'-to-3' directional mRNA decay pathway in the crenarchaeal clade of Archaea. In Bacteria the $5^{\prime}$-end of mRNAs is often protected by a tri-phosphorylated $5^{\prime}$-terminus and/or by stem-loop structures, while in Eukaryotes the cap-binding complex is responsible for this task. Here, we show that binding of translation initiation factor a/eIF2 $(\gamma)$ to the $5^{\prime}$-end of mRNA counteracts the $5^{\prime}$-to-3' exoribonucleolytic activity of Sso-RNase J in vitro. Hence, 5'-to-3' directional decay and $5^{\prime}$-end protection appear to be conserved features of mRNA turnover in all kingdoms of life.
\end{abstract}

Keywords: Archaea; Sulfolobus solfataricus; mRNA decay; exoribonuclease

\section{INTRODUCTION}

The pathways leading to mRNA degradation in all three kingdoms of life have lately gained increasing attention as an important step in gene regulation. In Bacteria and Eukaryotes the stability of mRNA is highly dependent on the $5^{\prime}$-end. In Escherichia coli, the decay of mRNA transcripts can be initiated by $5^{\prime}$-pyrophosphate removal by the enzyme RppH (Celesnik et al. 2007; Deana et al. 2008). The monophosphorylated mRNA is a preferred target for endonucleolytic cleavages generated by RNase E, which together with other proteins forms the degradosome (Callaghan et al. 2005; Carpousis 2007). The intermediate cleavage products resulting from successive RNase E cleavage are then further degraded by the $3^{\prime}$-to-5' exonucleases polynucleotide phosphorylase (PNPase), RNase II, RNase R, and oligoribonuclease (Fig. 1A; Deutscher 1993). At variance with E. coli, Bacillus subtilis possesses the $5^{\prime}$-to- $3^{\prime}$ exonuclease

Reprint requests to: Udo Bläsi, Max F. Perutz Laboratories, Department of Microbiology, Immunobiology and Genetics, University of Vienna, 1030 Vienna, Austria; e-mail: Udo.Blaesi@univie.ac.at; fax: 43-1-4277-9546.

Article published online ahead of print. Article and publication date are at http://www.rnajournal.org/cgi/doi/10.1261/rna.2418211.
RNase J1, which in addition to its exonuclease activity displays endonuclease activity on some substrates (Mathy et al. 2007). RNase J1 is a member of the $\beta$-CASP family of metallo- $\beta$-lactamases, comprising three domains-a metallo- $\beta$-lactamase, a $\beta$-CASP, and a C-terminal domain with the catalytic site located between the $\beta$-lactamase core and the $\beta$-CASP domain (de la Sierra-Gallay et al. 2008). Enzymes of this group include proteins acting on nucleic acid substrates and can be found in nearly every organism across the three kingdoms of life (Callebaut et al. 2002). In addition, the endonuclease RNase $\mathrm{Y}$, which is associated with glycolytic enzymes PNPase and RNase J1/2, seems to form the integral part of the degradosome of B. subtilis (Commichau et al. 2009; Lehnik-Habrink et al. 2010). As RNase Y has a large impact on overall mRNA stability in B. subtilis (Shahbabian et al. 2009), it appears that on most mRNAs, initial endonucleolytic cleavage by RNase $\mathrm{Y}$ and perhaps to a minor degree by RNase J1 precedes $5^{\prime}$-to- $3^{\prime}$ directional decay mediated by RNase J1 (Fig. 1B; Shahbabian et al. 2009; Yao and Bechhofer 2010). The 5'-terminal part of the mRNA can then be degraded by $3^{\prime}$-to-5' exonucleases (Oussenko et al. 2005; Condon 2010). Similar to E. coli RNase E, both B. subtilis RNase Y and RNase J1 


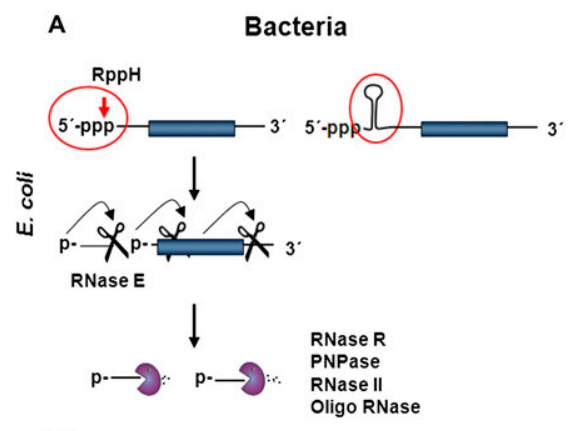

C

Eukaryotes
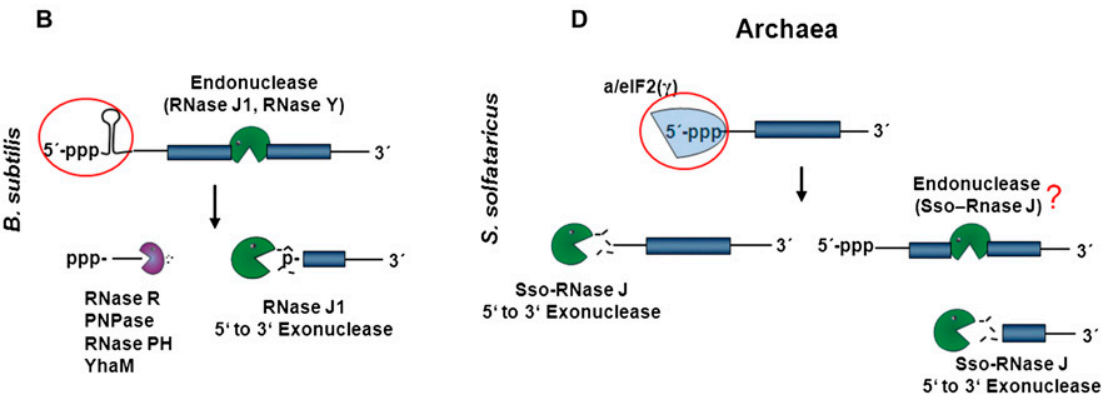

FIGURE 1. $5^{\prime}$-to- $3^{\prime}$ directional decay and $5^{\prime}$-end protection in Bacteria, Eukaryotes, and Archaea. (A) A tri-phosphorylated $5^{\prime}$-end and/or a $5^{\prime}$-terminal stem-loop structure on mRNAs can counteract the activities of RppH and RNase E in E. coli. Decay can be initiated by pyrophosphate removal, followed by endonucleolytic cleavage of the $5^{\prime}$-monophosphate-dependent RNase E. The resulting $5^{\prime}$-fragment is then degraded by the $3^{\prime}$-to- $5^{\prime}$ exonucleases oligoribonuclease (short stretches), PNPase, RNase R, or RNase II. Upon the first RNase E cleavage, the downstream fragment is endowed with a $5^{\prime}$-monophosphate, which can serve as a signal for the next endonucleolytic cut by RNase E. Repeated cycles of RNase E-dependent endonucleolytic cleavages and exoribonucleolytic decay can finally lead to $5^{\prime}$-to- $3^{\prime}$ directional decay of the mRNA. (B) In B. subtilis mRNA decay might be initiated by endonucleolytic cleavage in the $5^{\prime}$-part of the mRNA by either RNase Y or RNase J1. This generates a $5^{\prime}$-monophosphate, and the RNA can be degraded in the $5^{\prime}$-to- $3^{\prime}$ direction by RNase J1 and in the $3^{\prime}$-to- $5^{\prime}$ direction by RNase R, PNPase, RNase PH, or YhaM. As in E. coli, stem-loop structures at the 5'-end can have a protective function in $B$. subtilis. $(C)$ In Eukaryotes, deadenylation of the $3^{\prime}$-poly(A) tail generally proceeds in $5^{\prime}$-to- $3^{\prime}$ directional decay. Deadenylation and assembly of the Lsm1-7 protein complex at the $3^{\prime}$-end of the transcript induce decapping by the decapping enzyme DCP. The mRNA can then be degraded in the $5^{\prime}$-to- $3^{\prime}$ direction by an exoribonuclease, e.g., XRN1. $(D)$ In $S$. solfataricus, the protein a/eIF2 $(\gamma)$ can bind to the $5^{\prime}$-end of mRNAs and can thereby protect the mRNA from $5^{\prime}$-to- $3^{\prime}$ exonucleases, such as Sso-RNase J. Release of a/eIF2 $(\gamma)$ could render the mRNA vulnerable to Sso-RNase J. As an endonucleolytic activity by Sso-RNase J or the presence of an RNase Y-like endonuclease cannot be ruled out, it is possible that $5^{\prime}$-to- $3^{\prime}$ directional decay after removal of a/eIF2 $(\gamma)$ resembles that in B. subtilis (for references, see text).

prefer a $5^{\prime}$-monophosphate for their endo- or exonucleolytic activities, respectively (de la Sierra-Gallay et al. 2008; Shahbabian et al. 2009). In other words, progressive $5^{\prime}$-to- $3^{\prime}$ directional decay can be impeded by the tri-phosphorylated $5^{\prime}$-terminus of mRNA in Bacteria.

In Eukaryotes, mRNA decay is mainly catalyzed by exonucleases (Newbury 2006). Eukaryotic mRNAs generally have a 7-methylguanosine cap at their $5^{\prime}$-end and a poly(A) tail at their $3^{\prime}$-end. Removal of these terminal modifications is considered rate-limiting for mRNA decay (Fig. 1C; Tourriere et al. 2002). Translation initiation factor eIF4E binds to the 7-methylguanosine cap and thereby protects the cap structure from the decapping enzyme and consequently the mRNA from $5^{\prime}$-to-3' exonucleolytic decay (Tourriere et al. 2002).

Different RNases with endo- and exonucleolytic activity have been described in Archaea, but only a few of them have been shown to be involved in mRNA decay (Franzetti et al. 1997; EvguenievaHackenberg et al. 2003; Buttner et al. 2005; Even et al. 2005). The exosome is the best studied nucleolytic activity involved in mRNA decay in Archaea. It is a multi-subunit enzyme with a $3^{\prime}$-to$5^{\prime}$ exonucleolytic activity (EvguenievaHackenberg et al. 2003; Buttner et al. 2005; Portnoy et al. 2005). Archaeal mRNAs appear not to contain cap-like structures and lack othologs of eIF4E, decapping enzymes, and $5^{\prime}$-to-3' exonucleases, like XRNI. Furthermore, no RNase E orthologs have been found in Archaea. RNase J othologs were predicted for Euryarchaeota by bioinformatics (Even et al. 2005) and were recently experimentally confirmed in the hyperthermophilic Euryarchaeota Pyrococcus abyssi and Thermococcus kodakaraensis (Clouet-d'Orval et al. 2010).

We have recently shown that the $5^{\prime}$-end of mRNAs is protected from degradation by translation initiation factor a/eIF2 in Sulfolobus solfataricus (Hasenöhrl et al. 2008). The factor binds by virtue of the $\gamma$-subunit to the $5^{\prime}$-end of tri-phosphorylated mRNAs and thereby increases the stability of the 5 '-part of mRNAs. This implied a 5 '-end-dependent degradation mechanism by either a $5^{\prime}$-to- $3^{\prime}$ exonuclease like RNase J or a $5^{\prime}$-end-dependent endonuclease like RNase E. As no RNase belonging to the $\beta$-CASP family was predicted by bioinformatics for the archaeal clade of Crenarchaeota (Even et al. 2005), we used first an experimental approach to identify ribonucleolytic activities in $S$. solfataricus followed by a subsequent meta-structure analysis of the candidate proteins. This strategy identified the first crenarchaeal $5^{\prime}$-to- $3^{\prime}$ processive exonuclease in the model organism S. solfataricus. We further show that the activity of the enzyme encoded by the gene SSO0386 is counteracted by a/eIF2 $(\gamma)$ bound to the $5^{\prime}$-triphosphate end of RNA.

\section{RESULTS}

\section{Identification of a novel ribonuclease in $S$. solfataricus}

To identify new RNases in S. solfataricus, a zymogram assay (Kaberdin 2003; Kaberdin and McDowall 2003) was 
employed. Radioactively labeled $2508 \mathrm{fl}$ model mRNA was incorporated into the gel matrix, and S. solfataricus S100 extracts were loaded onto and separated in the gel, which was followed by renaturing steps. Degraded RNA, i.e., the presence of a RNA-degrading enzyme, was visible as a white band on the autoradiogram (Fig. 2A). Ribonucleolytic activity was only seen when the incubation was performed at $65^{\circ} \mathrm{C}$ but not at $37^{\circ} \mathrm{C}$ (Fig. $2 \mathrm{~A}$ ), indicating that the observed RNase activity originated from the thermophilic S. solfataricus. To identify these activities, the corresponding spots were analyzed by mass spectrometry. Candidate proteins were selected if their predicted function was linked to nucleic acid metabolism. The ORF SSO0386 encoded protein, which was annotated as a putative "mRNA 3'-end processing factor" (http://www-archbac.u-psud.fr/projects/ sulfolobus/), displayed a low sequence homology with bacterial RNase J from B. subtilis and Thermus thermophilus as well as to the euryarchaeal ortholog from P. abyssi. Sequence similarity of the SSO0386-encoded protein to these RNase J proteins was limited to certain areas, like motif 2 (Fig. 2B; Supplemental Fig. 1), which is a part of the catalytic domain of RNase J from T. thermophilus (de la Sierra-Gallay et al. 2008). The SSO0386-encoded protein has an $\sim 50$-amino-acid N-terminal extension and lacks the C-terminal domain, which is only present in bacterial RNase J proteins (Supplemental Fig. 1). In addition, the
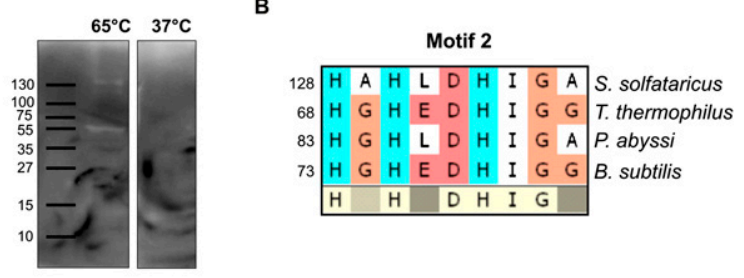

C

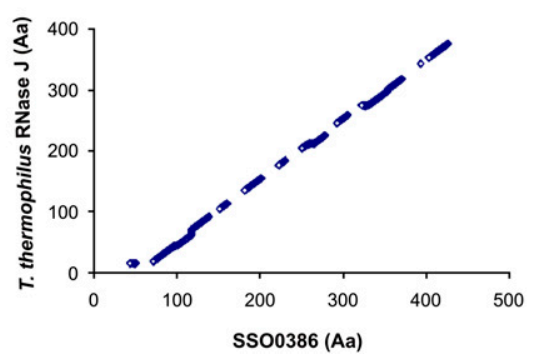

FIGURE 2. Identification of Sso-RNase $\mathrm{J}$ in $S$. solfataricus. (A) Zymogram assay with $S$. solfataricus $\mathrm{S} 100$ extracts incubated at $65^{\circ} \mathrm{C}$ or $37^{\circ} \mathrm{C}$. White bands indicate RNase activity in the extracts. (B) The catalytic domain (Motif 2) (see also Supplemental Fig. 1) described for T. thermophilus RNase J is conserved in Sso-RNase J. The numbers indicate the amino acid position of the first amino acid shown. $(C)$ The meta-structure alignment of Sso-RNase J and T. thermophilus RNase J revealed high structural homologies. The pairwise protein sequence alignment is based on calculated meta-structure parameters. As described in Materials and Methods, the scoring function for obtaining the optimal sequence match involves compactness and secondary-structure values.
SSO0386-encoded protein was annotated as a protein belonging to the $\beta$-lactamase superfamily. In fact, the five classical $\beta$-lactamase motifs and the three $\beta$-CASP motifs, a hallmark of proteins belonging to the $\beta$-CASP family of metallo- $\beta$-lactamases, are all present in the SSO0386encoded protein (Supplemental Fig. 1). The sequence of the SSO0386-encoded protein is highly conserved in the crenarchaeal clade of Archaea. A phylogenetic tree of putative homologues is shown in Supplemental Figure 2.

The ORF SSO0386-encoded protein was further scrutinized with regard to protein meta-structure (Konrat 2009). Briefly, the meta-structure analysis provides quantitative information on the local secondary structure and residue compactness for each residue position. The algorithm predicts how a particular local structural element is embedded in the context of the three-dimensional (3D) fold, either deeply buried or located on the surface, and thus exposed to the solvent (Konrat 2009). A meta-structure alignment of the SSO0386-encoded protein with the primary sequence of RNase J from T. thermophilus was performed. A high similarity between the two proteins at the meta-structural level was observed, except for the first $\sim 50$ amino acids (Fig. 2C). Taken together, these bioinformatics analyses classified the SSO0386-encoded protein as a potential RNase J ortholog, despite its very low overall sequence similarity with the known RNase J proteins.

\section{Sso RNase J displays 5' -to-3' directional activity}

To characterize the putative RNase activity encoded by ORF SSO0386, the corresponding gene was cloned and overexpressed, and the respective protein was purified in E. coli. The protein comprising 492 amino acids with an apparent molecular mass of 55,000 (Fig. 3A) is henceforth termed Sso-RNase J. The Sso-RNase J was first tested for its ability to degrade RNA using a zymogram assay. As shown in Figure 3A, RNA degradation was observed with SsoRNase J (lane 1) at the same position as with S. solfataricus S100 extracts (lane 2), strongly indicating that the ribonucleolytic activity seen within the S. solfataricus S100 extracts is conferred by Sso-RNase J.

To characterize the enzymatic properties of Sso-RNase J, two different, 40-nt-long, synthetic RNAs, with a tri-phosphate group at the $5^{\prime}$-end (PPP), harboring either a single radioactively labeled A nucleotide at the $5^{\prime}$-end or at the $3^{\prime}$-end, were used in further experiments. These RNAs are termed $5^{\prime}$-PPPGGA $^{*}-^{\prime \prime}-3^{\prime}$ and $5^{\prime}-$ PPP-GG-" $-A^{*}-3^{\prime}$, respectively. Several RNA-degrading enzymes, like bacterial RNase P, RNase $\mathrm{H}$, or RNase $\mathrm{E}$, require $\mathrm{Mg}^{++}$for activity (Carpousis et al. 2009). To test whether the RNase activity of Sso-RNase J depends likewise on $\mathrm{Mg}^{++}, 5^{\prime}$-PPP-GGA*-"-3' RNA was incubated with Sso-RNase $J$ in the presence and absence of $\mathrm{Mg}^{++}$. As shown in Figure 3B (middle panel), an RNAdegrading activity was only observed in the presence of $\mathrm{Mg}^{++}$. 
A

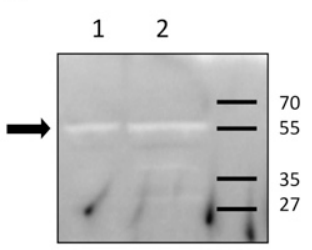

B

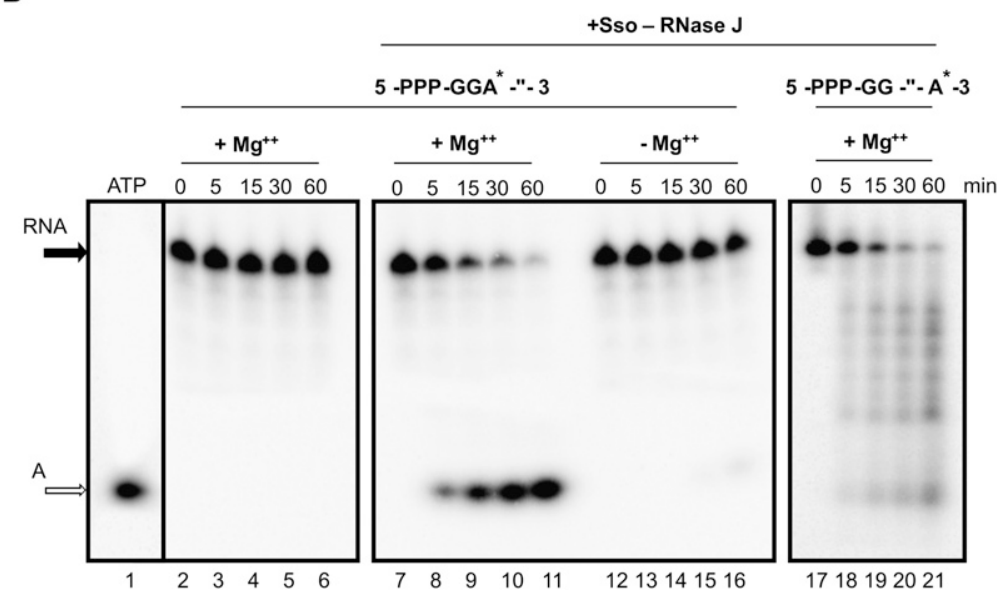

FIGURE 3. Sso-RNase $\mathrm{J}$ is an exoribonuclease displaying $5^{\prime}$-to- $3^{\prime}$ directionality. (A) Zymogram assays performed with purified Sso-RNase J (lane 1) and S. solfataricus S100 extracts (lane 2) at $65^{\circ} \mathrm{C}$. The arrow indicates the band corresponding to the RNase activity of SsoRNase J. ( $B$, left panel) $\left[\alpha_{-}{ }^{32} \mathrm{P}\right]$ ATP was loaded on the gel (lane 1$) .5^{\prime}$-PPP-GGA*-" $3^{\prime}$ RNA was incubated for 0 to $60 \mathrm{~min}$ at $65^{\circ} \mathrm{C}$ in the absence of Sso-RNase J (lanes 2-6). (Middle panel) Incubation of $5^{\prime}$-PPP-GGA* ${ }^{\star} "-3^{\prime}$ RNA with Sso-RNase J in the presence (lanes 7-11) and absence of $\mathrm{Mg}^{++}$(lanes 12-16). (Right panel) Incubation of $5^{\prime}$-PPP-GG-"-A*-3' RNA with Sso-RNase J for 0 to $60 \mathrm{~min}$ in the presence of $\mathrm{Mg}^{++}$(lanes 17-21). The filled arrow indicates the full-length RNA, and the open arrow the single A nucleotide.

Next, we addressed the question whether Sso-RNase J displays endo- or exonucleolytic activity and attempted to determine the directionality of the RNase activity. As shown in Figure 3B, upon addition of Sso-RNase J to either RNA substrate, the final degradation product obtained was a single nucleotide, indicating an exo- rather than an endo-nucleolytic activity. The degradation pattern of the $3^{\prime}$-end-labeled 5'-PPP-GG-"-A*-3' RNA showed a "smear" and several bands (Fig. 3B, right panel, lanes 17-21), whereas the $5^{\prime}$-endlabeled 5'-PPP-GGA*-"-3' RNA shows only the final degradation product, i.e., the single nucleotide (Fig. 3B, middle panel, lanes 7-11). Taken together, these results indicated that Sso-RNase J functions as a $5^{\prime}$-to-3' exonuclease, which is dependent on $\mathrm{Mg}^{++}$.

\section{A mono-phosphorylated $5^{\prime}$-end is a conserved element for the activity of $5^{\prime}$-end-dependent ribonucleases}

Primary transcripts in Bacteria have a tri-phosphate group at the $5^{\prime}$-end, and several studies have revealed the influence of $5^{\prime}$-termini on the half-lives of primary tran- scripts (Mackie 1998; Even et al. 2005). Celesnik et al. (2007) have shown that enzymatic pyrophosphate removal from the $5^{\prime}$-terminus permits RNase $\mathrm{E}$ to cleave substrates faster when compared to triphosphate-containing termini. To determine whether Sso-RNase J is sensitive to the phosphorylation state of the $5^{\prime}$-end of RNA, the cleavage rate of $5^{\prime}$-PPP-GGA*"-3', 5'-P-GGA*-"-3', and 5'-OH-GGA*"-3' RNA was compared. As shown in Figure 4, when compared with the triphosphorylated RNA, Sso-RNase J displayed a twofold higher velocity in degrading mono-phosphorylated RNA and RNA bearing a 5'-hydroxyl group.

\section{No evidence for pyrophosphate removal at the 5 '-terminus of RNA in S. solfataricus}

In E. coli, the pyrophosphohydrolase $\mathrm{RppH}$ can initiate mRNA decay by 5 '-pyrophosphate removal (Celesnik et al. 2007; Deana et al. 2008). In light of our findings that Sso-RNase J exhibited a moderate preference for mono- over tri-phosphorylated RNA substrates, we tested whether pyrophosphate removal occurs in S. solfataricus. A Phosphorylation Assay By Ligation of Oligonucleotides (PABLO) was applied, which has been used to demonstrate the existence of mono-phosphorylated 5'-termini in E. coli (Celesnik et al. 2007). Briefly, this assay is based on the ability of T4 DNA ligase to join a DNA oligonucleotide (oligo $\mathrm{X}$ ) to mono-phosphorylated RNA when their ends are juxtaposed via annealing to a bridging oligonucleotide (oligo Y) (Fig.

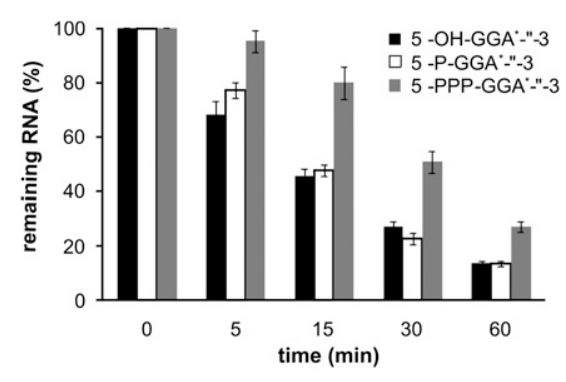

FIGURE 4. Sso-RNase J displays an enhanced degradation rate of mono-phosphorylated than of tri-phosphorylated mRNA. The graph shows the remaining RNA at the indicated times upon degradation with Sso-RNase J. The values are an average of three independent experiments. The values are derived from RNase assays as shown in Figure 3B. (Black bars) 5'-OH-GGA*-"-3' RNA; (white bars) $5^{\prime}-$ P-GGA*-"-3' RNA; (gray bars) 5'-PPP-GGA* -"-3' RNA. 


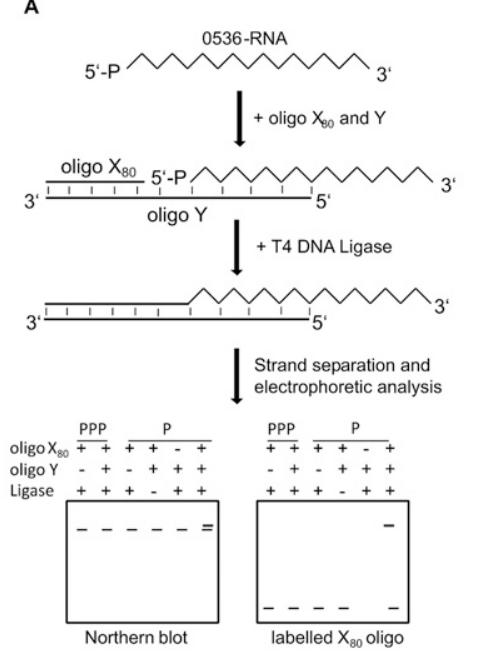

D

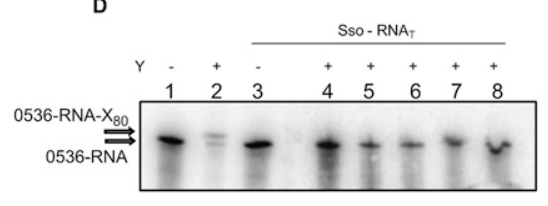

B



C

0536-RNA-X

$\begin{array}{llllllllllll}1 & 2 & 3 & 4 & 5 & 6 & 7 & 8 & 9 & 10\end{array}$

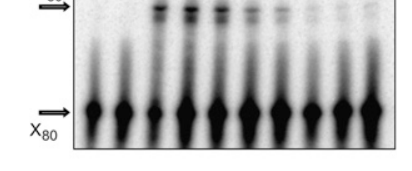

E

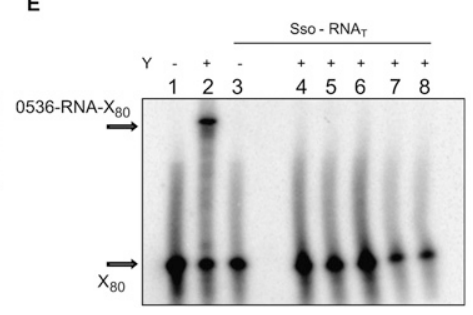

FIGURE 5. PABLO analysis reveals no evidence for $5^{\prime}$-pyrophosphate removal. (A) Schematic outline of the PABLO analysis for determination of the $5^{\prime}$-phosphorylation state of RNA. T4 DNA ligase joins oligo $\mathrm{X}_{80}$ to $5^{\prime}$-mono-phosphorylated, but not to $5^{\prime}$-tri-phosphorylated RNA annealed to the bridging oligo Y. If ligation occurs an extended DNA-RNA chimera can be detected by either Northern blot analysis using a probe or directly on the autoradiogram, when oligonucleotide $\mathrm{X}_{80}$ is radioactively labeled. $(B, C)$ Tri-phosphorylated PPP-0536-RNA (lane 1) or different mixtures ([lanes 2,3] 65\%; [lane 4] 50\%; [lane 5] 33\%; [lane 6] 20\%; [lane 7] 10\%; [lane 8] 5\%; [lane 9] 2\%; [lane 10] 1\% mono-phosphorylated P-0536-RNA) of mono- and triphosphorylated 0536-RNA (lanes 2-10) were used to determine the efficiency of the PABLO assay. No Y-oligo (lane 2) or $\mathrm{Y}_{\text {invitro_0536 }}$ (lanes 1,3-10) was added to the ligation mixture. Detection of the ligation products was achieved by Northern blot analysis $(B)$ or directly on the autoradiogram as described above $(C)$. (Arrows) The 0536-RNA, the radioactively labeled $\mathrm{X}_{80}$ oligo, and the 0536-RNA-X 80 ligation product. $(D, E)$ Partially mono-phosphorylated (lanes $1,2)$ and total RNA $\left(\mathrm{RNA}_{\mathrm{T}}\right.$ ) from S. solfataricus (lanes 3-8) was subjected to PABLO analysis.

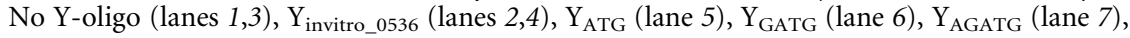
or $\mathrm{Y}_{\mathrm{GAGATG}}$ (lane 8 ) was added to the ligation mixture. Detection of the ligation products was achieved by Northern blot analysis $(D)$ or directly on the autoradiogram as described above $(E)$. (Arrows) The 0536-RNA, the radioactively labeled $\mathrm{X}_{80}$ oligo, and 0536-RNA- $\mathrm{X}_{80}$ ligation product.

5A; Celesnik et al. 2007). If pyrophosphate removal exists in S. solfataricus, mono-phosphorylated mRNAs should be present, which can be potentially detected in the PABLO assay. A slightly modified PABLO assay was additionally performed, where the radioactively labeled oligonucleotide $\mathrm{X}_{80}$ was used for ligation to the respective $5^{\prime}$-terminus of mRNA. The modified assay increased the sensitivity approximately fivefold but did not allow quantification of the ratio of mono- and tri-phosphorylated RNA. As the mRNA encoded by ORF SSO0536 (encodes an S-adenosylmethionine decarboxylase proenzyme) is within $\sim 420 \mathrm{nt}$, rather short, and highly transcribed (Wurtzel et al. 2010), this transcript was used in the PABLO experiments. Initial Northern blot experiments with in vitro transcribed 0536RNA and total RNA from S. solfataricus allowed us to quantify the amount of 0536-RNA in the total RNA preparation (data not shown). The same amountsas present in total RNA $(10 \mu \mathrm{g})$ of $S$. solfataricus - were used of in vitro transcribed 0536-RNA in an initial PABLO assay to determine the efficiency of the ligation assay (Fig. 5B,C). Using different ratios of mono- and tri-phosphorylated $0536-\mathrm{RNA}$, we could detect $5 \%$ mono-phosphorylated RNA by Northern blot analysis (Fig. 5B) and even 1\% with the modified assay (Fig. 5C) using radioactively labeled oligonucleotide $\mathrm{X}_{80}$. In E. coli, $\sim 10 \%-15 \%$ of the studied mRNA was reported to be mono-phosphorylated (Celesnik et al. 2007). However, using total RNA from S. solfataricus we were not able to detect mono-phosphorylated RNA, neither in the Northern blot using a labeled probe (Fig. 5D) nor in the modified assay using the labeled oligonucleotide as a substrate for ligation (Fig. 5E). To exclude an inaccuracy in the determination of the $5^{\prime}$-end of 0536-mRNA by primer extension (see Materials and Methods), three additional Y-oligos containing one, two, or three additional $5^{\prime}$-nucleotides according to the genomic sequence were also used in the PABLO assay. However, with these bridging oligonucleotides, no ligation product was detected either (Fig. $5 \mathrm{D}, \mathrm{E})$. The PABLO assay was also performed with two other mRNAs (data not shown). However, also in this set of experiments, no evidence for the presence of mono-phosphorylated 5 '-termini was obtained. Collectively, these results provided no evidence for pyrophosphate removal as a triggering event preceding mRNA decay in S. solfataricus.

At least in E. coli and Eukaryotes, removal of the protective $5^{\prime}$-tri-phosphate and the cap structure is accomplished by the pyrophosphatase $\mathrm{RppH}$ and the decapping enzyme Dcp2, respectively, both of which belong to the Nudix protein family (Tourriere et al. 2002; Deana et al. 2008). Despite no evidence for the presence of a pyrophosphohydrolase function in S. solfataricus (Fig. 5), we searched for annotated proteins that show signatures of Nudix proteins, i.e., the highly conserved 23-residue sequence motif or Nudix box (Mildvan et al. 2005). Two ORFs-SSO3167 and 
SSO2278-in S. solfataricus were annotated to encode proteins of the Nudix family. We cloned both genes, purified the corresponding proteins from E. coli, and tested for a pyrophosphohydrolase activity. However, using different buffer and temperature conditions, we were unable to demonstrate pyrophosphate removal (data not shown).

\section{Protection of the mRNA 5 '-terminus by a/elF2 $(\gamma)$}

In Bacteria and Eukaryotes, the $5^{\prime}$-end of mRNAs is protected by secondary structures or by the CAP complex, respectively. We have recently shown that the trimeric translation initiation factor a/eIF2 binds via its $\gamma$-subunit to the $5^{\prime}$-tri-phosphorylated terminus of mRNA and thereby protects mRNAs from $5^{\prime}$-to- $3^{\prime}$ directional decay in vitro and in vivo (Hasenöhrl et al. 2008). Accordingly, we anticipated that binding of a/eIF2 $(\gamma)$ to the $5^{\prime}$-end of the RNA should prevent or at least slow down $5^{\prime}$-to-3' directional decay by Sso-RNase J. To test this, $5^{\prime}$-PPP$\mathrm{GGA}^{*}$-" $^{\prime} 3^{\prime}$ RNA was used, and the decay of the RNA by Sso-RNase $\mathrm{J}$ was monitored in the presence and absence of a/eIF2 $(\gamma)$. As shown in Figure 6A, when a/eIF2 $(\gamma)$ was preincubated with $5^{\prime}$-PPP-GGA*-" $3^{\prime}$ RNA, i.e. pre-bound to the $5^{\prime}$-end of the RNA (Hasenöhrl et al. 2008), the RNA was protected from $5^{\prime}$-to-3' directional decay by Sso-RNase J. This confirmed the $5^{\prime}$-end-dependent activity of SsoRNase J and the protective function of a/eIF2 $(\gamma)$. In contrast, when the a/eIF $2 \alpha$ subunit, which does not bind to the 5 '-terminus of RNA (Hasenöhrl et al. 2008), was pre-incubated with 5'-PPP-GGA*-"-3' RNA, no protection from Sso-RNase J was observed (Fig. 6A). Similarly, when monophosphorylated 5'-P-GGA*-"-3' RNA was used in the
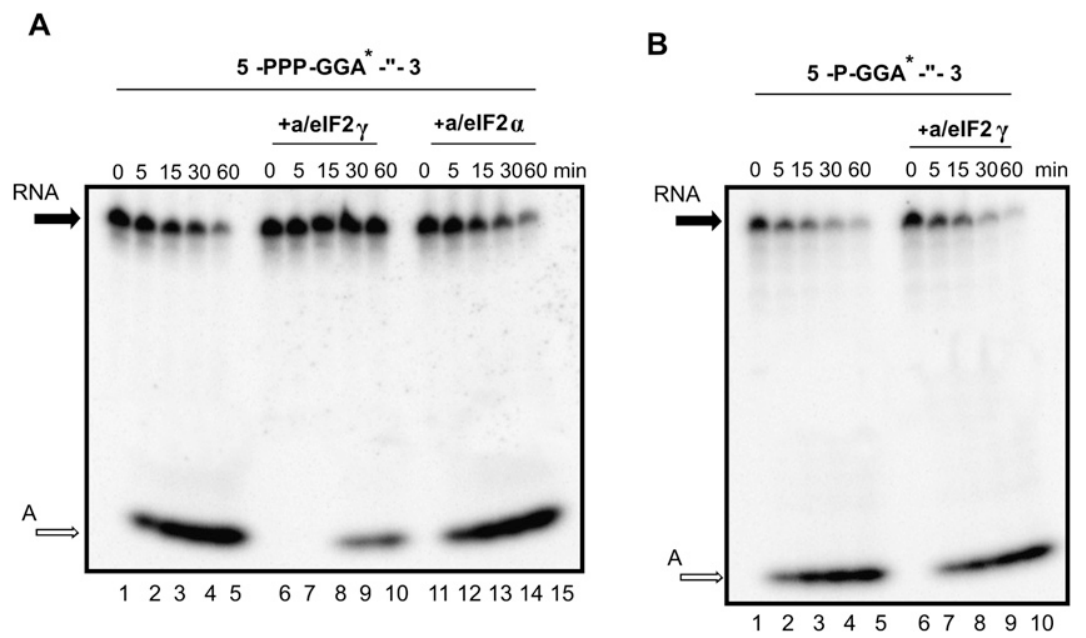

FIGURE 6. The a/eIF2 $(\gamma)$-subunit protects RNA from degradation by Sso-RNase J. (A) $5^{\prime}$ PPP-GGA*-"-3' RNA $(0.25 \mu \mathrm{M})$ was incubated for 0 to $60 \mathrm{~min}$ at $65^{\circ} \mathrm{C}$ in the presence of SsoRNase J in the absence (lanes $1-5)$ or presence (lanes 6-10) of pre-bound a/eIF2 $(\gamma)(0.5 \mu \mathrm{M})$ or in the presence of a/eIF2 $(\alpha)(0.5 \mu \mathrm{M})$ (lanes 11-15). (B) $5^{\prime}$-P-GGA*-"-3' RNA was incubated for 0 to $60 \mathrm{~min}$ at $65^{\circ} \mathrm{C}$ in the presence of Sso-RNase J in the absence (lanes 1-5) or presence (lanes 6-10) of a/eIF2 $\gamma$. The filled arrow indicates the full-length RNA and the open arrow the single A nucleotide. assay, pre-incubation of the RNA with a/eIF2 $(\gamma)$ did not result in protection of the RNA from $5^{\prime}$-to-3' decay by SsoRNase J (Fig. 6B), which was in agreement with our previous data showing that $\mathrm{a} / \operatorname{eIF} 2(\gamma)$ does not bind to monophosphorylated 5'-termini (Hasenöhrl et al. 2008).

\section{DISCUSSION}

When compared to RNase J from B. subtilis, T. thermophilus, and P. abyssi, Sso-RNase J displays sequence conservation in the putative catalytic domain as well as in other motifs (Fig. 2; Supplemental Fig. 1), but does not share a high similarity in the overall protein sequence with these enzymes. Although the C-terminal domain of T. thermophilus RNase J was found to be essential for its function (de la Sierra-Gallay et al. 2008), Sso-RNase J as well as other putative RNase J homologs from Archaea lack this C-terminal domain (Supplemental Fig. 1). These dissimilarities in primary sequence might have initially compromised the identification of RNase J orthologs in Crenarchaeota by homology searches. However, the primary sequence-based meta-structure alignment (Konrat 2009) of T. thermophilus RNase J and Sso-RNase J clearly revealed structural similarities (Fig. 2C). Thus, the combined bioinformatics search for functional motifs in combination with protein meta-structure analysis, which views the protein structure as a network of interacting residues, offers a valuable tool to identify similar/identical protein functions in the absence of high primary sequence homology.

We have characterized the Sso-RNase J as a $5^{\prime}$-to- $3^{\prime}$ directional exonuclease with a moderate preference for 5 '-mono- over tri-phosphorylated ends. In E. coli, $\sim 10 \%-$ $15 \%$ of selected mRNAs were found to be mono-phosphorylated (Celesnik et al. 2007), a level we would have anticipated to detect with the modified PABLO assay. Clearly, we cannot exclude that in $S$. solfataricus only a very small fraction of mRNA is dephosphorylated, and therefore escaped our assay. Nevertheless, the seeming absence of mRNA 5 -end dephosphorylation is reminiscent to the situation in B. subtilis. Although B. subtilis RNase J1 (Mathy et al. 2007) and RNase Y (Shahbabian et al. 2009) show a preference for $5^{\prime}$ mono-phosphorylated substrates, no RppH-like activity has been detected in B. subtilis, and it is unclear if a dephosphorylation event triggering mRNA decay exists in this organism (Deikus et al. 2008). The B. subtilis RNase J1 has a dual nuclease activity, acting as an exo- or an endonuclease, whereby the latter activity seems to be exerted only on a few substrates 
(Even et al. 2005; Mathy et al. 2007). Models have been put forward wherein an initial endonucleolytic cleavage by either RNase Y or RNase J1 creates a new mono-phosphorylated $5^{\prime}$-terminus, which then becomes a preferred substrate for the $5^{\prime}$-to-3' processive exoribonucleolytic activity of RNase J1 (Mathy et al. 2007; Yao and Bechhofer 2010). Using synthetic RNAs (Fig. 3) as well as $5^{\prime}$-end-labeled natural mRNAs from S. solfataricus (data not shown), we obtained no hints for an endonucleolytic activity of Sso-RNase J. However, as the endonuclease activity of $B$. subtilis RNase J1 was only observed with very few RNA targets (Even et al. 2005), we cannot exclude that Sso-RNase J displays endonuclease activity on certain mRNAs or that an endonuclease similar to the situation in B. subtilis sets the stage for RNase J in S. solfataricus (Fig. 1D). On the other hand, it has been reported that RNase J1 from B. subtilis as well as from Sinorhizobium meliloti has a function in rRNA maturation (Mathy et al. 2007; Madhugiri and EvguenievaHackenberg 2009). Hence, this observation opens up the possibility that Sso-RNase J may not only act on mRNAs but also on non-coding RNAs.

$5^{\prime}$-End protection of mRNAs is occurring in all three kingdoms of life (Fig. 1; Tourriere et al. 2002; Mathy et al. 2007; Clouet-d'Orval et al. 2010). Interestingly, in the three kingdoms, different means are exploited to protect the tri-phosphate group and consequently the body of the mRNA from 5'-to-3' directional decay. In Eukaryotes, the 7-methylguanosine cap is attached to the tri-phosphate bridge at the $5^{\prime}$-end of mRNAs, and the cap structure is additionally protected by the cap-binding complex (Tourriere et al. 2002). In Bacteria, where the mRNA half-lives are rather short, protection is often achieved by stem-loop structures at the 5'-end (Condon 2003; Belasco 2010). Interestingly, a stem-loop located at the immediate $5^{\prime}$-end of a mRNA, i.e., the absence of $5^{\prime}$-nucleotide(s) in singlestranded conformation, was shown to inhibit pyrophosphate removal and to slow down $5^{\prime}$-to-3' decay (Celesnik et al. 2007).

In contrast to Eukaryotes, archaeal mRNAs lack a cap structure and at least in hyperthermophilic Archaea as in S. solfataricus, the formation of stable stem-loop structures is believed to be compromised by high temperature. In S. solfataricus, the translation initiation factor a/eIF2 $(\gamma)$ was shown to bind to the $5^{\prime}$-tri-phosphate terminus of mRNA and to protect from $5^{\prime}$-to- $3^{\prime}$ directional decay (Hasenöhrl et al. 2008). Herein, we have shown that a/eIF2 $(\gamma)$ counteracts the activity of Sso-RNase J (Figs. 1, 6). This protection might be of particular importance in light of the prevalence of leaderless mRNAs in S. solfataricus (She et al. 2001). These mRNAs start directly or only a few nucleotides upstream of the start codon and can therefore be considered to be particularly vulnerable to a $5^{\prime}$-to- $3^{\prime}$ exoribonuclease, such as Sso-RNase J. Interestingly, $5^{\prime}$-end protection by a/eIF2 $(\gamma)$ was also observed with the respective proteins from other Sulfolobus spp. and with that of the crenarchaeum Pyrobaculum aerophilum, all of which encode putative RNAse-J proteins (Supplemental Fig. 2).

In E. coli and in Eukaryotes, dedicated enzymes have been identified that remove either the protective triphosphate terminus or the cap structure, which in both cases leaves a mono-phosphorylated 5 '-terminus (Newbury 2006; Deana et al. 2008), in turn generating suitable substrates that permit $5^{\prime}$-to- $3^{\prime}$ directional decay. It was not surprising to find that a/eIF2 bound to the $5^{\prime}$-end of leaderless mRNAs prevented $30 \mathrm{~S}$ translation initiation complex formation in vitro (D Hasenöhrl and U Bläsi, unpubl.). Clearly, this finding poses the question as to the recycling of a/eIF2 from tri-phosphate ends, which would not only be required for translation of a/eIF2-protected mRNAs, but also for their $5^{\prime}$-to-3' decay (Fig. 1D).

\section{MATERIALS AND METHODS}

\section{Preparation of RNA}

5'-PPP-GGA*-"-3' and 5'-PPP-GG-" - A $^{*}-3^{\prime}$ RNA were prepared as follows: A DNA oligonucleotide containing the T7-Promotor (5'-GGGCTCTAGAGTAATACGACT CACTATAGG-3') was first hybridized to a second oligonucleotide, either oligo-GGA* $\left(5^{\prime}\right.$-AGA CAGAAACCACAGAACGAGACAGAAACCACAGAACGTCCTA TAGTGAGTCGTATTAC-3') or oligo-GG-"-A* (5'-GTCAGAAA CCACAGAACGAGACAGAAACCACAGAACGACCTATAGTGAG TCGTATTAC- $3^{\prime}$ ), by heating to $90^{\circ} \mathrm{C}$ and slowly cooling to $37^{\circ} \mathrm{C}$. The hybrids were then used as template for in vitro transcription using the Ambion MEGAshortscript T7 Kit. 5'-P-GGA*-"-3' RNA and $5^{\prime}-\mathrm{OH}-\mathrm{GGA}^{*}-^{\prime \prime}-3^{\prime}$ RNA were generated by treating $5^{\prime}$-PPPGGA $^{*}{ }^{\prime \prime}-3^{\prime}$ RNA either with Tobacco Acid Pyrophosphatase (Biozyme) or FastAP (Fermentas) as specified by the manufacturer.

0536 mRNA was prepared using $S$. solfataricus chromosomal DNA and 0536_FP (5'-TTAATACGACTCACTATAGGATGTCA GAACGGGAGGTATTACAAA-3') and 0536_RP (5' -CATAGACA GTTGCCGAATGAATTA- $3^{\prime}$ ) to generate a PCR template for in vitro transcription using the Ambion MEGAshortscript T7 Kit. To produce partially mono-phosphorylated 0536-RNA, a 10-fold excess of GMP over GTP was used in the in vitro transcription reaction.

$2508 \mathrm{fl}$ mRNA was prepared and internally labeled with $\left[\alpha-{ }^{32} \mathrm{P}\right]$ ATP as described (Hasenöhrl et al. 2008). All RNAs were gel-purified.

\section{Purification of Sso-RNase J and of the $\alpha$ - and $\gamma$-subunits of a/elF2}

The gene encoding Sso-RNase J was cloned by means of PCR amplification from S. solfataricus $\mathrm{P} 2$ genomic DNA. The forward primer SSO0386_FP (5'-TTCTTCCATGGCATTTGTTTTCATAA CGGTAGG-3') and the reverse primer SSO0386_RP (5'-AAGAA CTCGAGTAAACTAATTTCTTGACCATTTTCCG-3') were used for PCR. They contained restriction sites (underlined; NcoI, XhoI) for insertion into the corresponding sites of the expression vector pET28b (Novagen). The recombinant plasmid was sequenced and transformed into E. coli BL21 (DE3) (Stratagene). The synthesis of Sso-RNase J was induced for $3 \mathrm{~h}$ with $1 \mathrm{mM}$ IPTG at an $\mathrm{OD}_{600}$ of 0.5 . The cells were lysed, and the cell extracts were heated for 10 
$\min$ at $70^{\circ} \mathrm{C}$ and centrifuged at $10,000 \mathrm{~g}$ for $10 \mathrm{~min}$ to precipitate the E. coli proteins. The recombinant protein, which contained an $\mathrm{N}$-terminal tag of six histidines, was purified to homogeneity by affinity chromatography on Ni-NTA agarose following standard protocols (QIAGEN). The purified protein was dialyzed against storage buffer $(10 \mathrm{mM}$ MOPS, $200 \mathrm{mM} \mathrm{KCl}, 10 \mathrm{mM} \beta$-mercaptoethanol, and $10 \%$ glycerol) and stored at $-80^{\circ} \mathrm{C}$ in aliquots.

The a/eIF $2 \alpha$ - and $\gamma$-subunits were prepared as described before (Pedulla et al. 2005).

\section{Zymogram}

Internally radioactive-labeled $2508 \mathrm{fl} \mathrm{mRNA}$ was added to the gel mixture (12\% SDS polyacrylamide gel) before the gel was cast. $S$. solfataricus S100 extract was prepared as described before (Londei et al. 1986). Electrophoresis was carried out at $100 \mathrm{~V}$ for $\sim 1 \mathrm{~h}$. The gel was incubated overnight in $25 \%$ isopropanol on a shaking platform at room temperature. The following renaturing and incubation steps were carried out at room temperature: $2 \times 15 \mathrm{~min}$, $6 \mathrm{M}$ guanidine chloride $(\mathrm{GnCl})$ in incubation buffer (IB; $5 \mathrm{mM}$ HEPES at $\mathrm{pH}$ 7, $10 \mathrm{mM} \mathrm{KCl,} 10 \mathrm{mM} \mathrm{Mg}[\mathrm{OAc}]_{2}$ ) and $0.1 \mathrm{mM} \mathrm{DTT}$; $15 \mathrm{~min}, 3 \mathrm{M} \mathrm{GnCl}$ in IB and $0.1 \mathrm{mM}$ DTT; $15 \mathrm{~min}, 1.5 \mathrm{M} \mathrm{GnCl}$ in IB and $0.1 \mathrm{mM}$ DTT; $15 \mathrm{~min}, 0.75 \mathrm{M} \mathrm{GnCl}$ in IB and $0.1 \mathrm{mM}$ DTT; $15 \mathrm{~min}, 0.375 \mathrm{M} \mathrm{GnCl}$ in IB and $0.1 \mathrm{mM}$ DTT; $15 \mathrm{~min}, 0.1 \mathrm{M} \mathrm{GnCl}$ in IB and $0.1 \mathrm{mM}$ DTT; $15 \mathrm{~min}, \mathrm{IB}$ and $0.1 \mathrm{mM} \mathrm{DTT} ; 90 \mathrm{~min}$, IB and $1 \mathrm{mM}$ DTT at $65^{\circ} \mathrm{C}$. The gel was dried and subjected to autoradiography using a Typhoon 8600 PhosphorImager.

\section{RNase activity assay}

Sso-RNase $\mathrm{J}$ activity was assayed in a $5-\mu \mathrm{L}$ reaction volume by incubating the respective RNA $(0.25 \mu \mathrm{M})$ with $100 \mathrm{ng}$ of enzyme for 0 to $60 \mathrm{~min}$ at $65^{\circ} \mathrm{C}$ in incubation buffer ( $5 \mathrm{mM} \mathrm{HEPES}$ at $\mathrm{pH}$ 7, $\left.10 \mathrm{mM} \mathrm{KCl}, 10 \mathrm{mM} \mathrm{Mg}[\mathrm{OAc}]_{2}\right)$. The a/eIF2 $\gamma(0.5 \mu \mathrm{M})$ and the a/eIF2 $\alpha$ subunit $(0.5 \mu \mathrm{M})$ were added to the reaction mixture and incubated for $2 \mathrm{~min}$ at $65^{\circ} \mathrm{C}$ before addition of Sso-RNase J. The reactions were terminated by addition of $5 \mu \mathrm{L}$ of $95 \%$ formamide/ $20 \mathrm{mM}$ EDTA and loaded on 20\% PAA-7 M urea gels.

\section{PABLO assay}

Total RNA from S. solfataricus $(10 \mu \mathrm{g})$ or in vitro-transcribed RNA was combined with oligo $\mathrm{X}_{80}(0.4 \mu \mathrm{M}$ cold or $5 \mathrm{nM}$ radioactively labeled oligo) and oligo $\mathrm{Y}(0.08 \mu \mathrm{M})$ in a final volume of $50 \mu \mathrm{L}$, heated for $5 \mathrm{~min}$ to $75^{\circ} \mathrm{C}$, slowly cooled to $30^{\circ} \mathrm{C}$, and then chilled for at least $1 \mathrm{~min}$ on ice. Buffer $\mathrm{A}(30 \mu \mathrm{L})$ containing Tris- $\mathrm{HCl}(100 \mathrm{mM}, \mathrm{pH} 7.8), \mathrm{MgCl}_{2}(27 \mathrm{mM})$, ATP $(1.9 \mathrm{mM})$, RNasin (4 units/ $\mu \mathrm{L})$, and T4 DNA ligase (0.4 Weiss units $/ \mu \mathrm{L})$ was added, and the ligation reaction was carried out for $3 \mathrm{~h}$ at $37^{\circ} \mathrm{C}$. The reaction was terminated by adding EDTA $(1 \mu \mathrm{L}$, $0.5 \mathrm{M}$ ), and the products were phenol-extracted, ethanolprecipitated, and analyzed by either Northern blotting or directly on the gel when radioactively labeled oligo $\mathrm{X}_{80}$ was used.

The Y oligos used to examine the phosphorylation state of S. solfataricus transcripts were designed to bring the $3^{\prime}$-end of oligo $\mathrm{X}$ in juxtaposition to the $5^{\prime}$-end of the RNA under study. The RNA 5'-ends were identified by primer extension, which matched the predicted $5^{\prime}$-ends from a recent single-base resolution transcriptome analysis (Wurtzel et al. 2010). The sequence of oligos used in the PABLO analysis of $S$. solfataricus RNA were $\mathrm{X}_{80}$
(5'-CСССССССССССССССССССССССССССССССССССС CCСССССССССССССССССССGAACAATATGAATGATAAC TTG-3'), Y invitro_0536 $_{\text {(5'-AATTTTTTGTAATACCTCCCGTTCT }}$ GACATCCCAAGTTATCATTCATATTGTTC- $\left.3^{\prime}\right), \mathrm{Y}_{\text {ATG }}\left(5^{\prime}\right.$-AAT TTTTTGTAATACCTCCCGTTCTGACATCAAGTTATCATTCAT ATTGTTC-3'), Y GATG (5'-AATTTTTTGTAATACCTCCCGTTC TGACATCCAAGTTATCATTCATATTGTTC-3'), $\mathrm{Y}_{\text {AGATG }}\left(5^{\prime}\right.$-AAT TTTTTGTAATACCTCCCGTTCTGACATCTCAAGTTATCATTC ATATTGTTC- $3^{\prime}$ ), Y GAGATG $\left(5^{\prime}\right.$-AATTTTTTGTAATACCTCCCG TTCTGACATCTCCAAGTTATCATTCATATTGTTC-3'), and 0536NB (5' -CCGAACACATGTTTCCCTATTATCC-3').

\section{Meta-structure analysis}

The strategy followed the dynamic programming algorithm of Needleman and Wunsch (1970) for aligning sequences based on pairwise amino acid similarities. Instead of using well-established measures for amino acid similarities, calculated meta-structure parameters derived from the primary sequence are applied to define pairwise similarity matrices. For the calculation of a suitable scoring function, both secondary structure and compactness values are used. A residue-residue match was considered acceptable if the pairwise $C_{i}$ and $S_{i}$ differences were below an empirically optimized threshold value $\left(\Delta C_{i}=250 ; \Delta S_{i}=150\right)$. For the quantification of alignments, stretches of 30 amino acids were considered. No penalty or moderate penalties were introduced if more than 27 (weight: 100) or between 15 and 27 residues (weight: 30) were considered as acceptable; otherwise, penalties were introduced (fewer than 15 matches: -25 ; no match: -50 ). The gap penalty value was optimized to 1 (Konrat 2009).

\section{SUPPLEMENTAL MATERIAL}

Supplemental material can be found at http://www.rnajournal.org.

\section{ACKNOWLEDGMENTS}

This work was supported by grant P21560 from the Austrian Science Fund to U.B. We thank Dr. Markus Schmid for his support in creating Supplemental Figure S2.

Received August 17, 2010; accepted October 7, 2010.

\section{REFERENCES}

Belasco JG. 2010. All things must pass: contrasts and commonalities in eukaryotic and bacterial mRNA decay. Nat Rev Mol Cell Biol 11: 467-478.

Buttner K, Wenig K, Hopfner KP. 2005. Structural framework for the mechanism of archaeal exosomes in RNA processing. Mol Cell 20: 461-471.

Callaghan AJ, Marcaida MJ, Stead JA, McDowall KJ, Scott WG, Luisi BF. 2005. Structure of Escherichia coli RNase E catalytic domain and implications for RNA turnover. Nature 437: 1187-1191.

Callebaut I, Moshous D, Mornon JP, de Villartay JP. 2002. Metallo$\beta$-lactamase fold within nucleic acids processing enzymes: the $\beta$-CASP family. Nucleic Acids Res 30: 3592-3601.

Carpousis AJ. 2007. The RNA degradosome of Escherichia coli: an mRNA-degrading machine assembled on RNase E. Annu Rev Microbiol 61: 71-87. 
Carpousis AJ, Luisi BF, McDowall KJ. 2009. Endonucleolytic initiation of mRNA decay in Escherichia coli. Prog Mol Biol Transl Sci 85: $91-135$.

Celesnik H, Deana A, Belasco JG. 2007. Initiation of RNA decay in Escherichia coli by 5' pyrophosphate removal. Mol Cell 27: 79-90.

Clouet-d'Orval B, Rinaldi D, Quentin Y, Carpousis AJ. 2010. Euryarchaeal $\beta$-CASP proteins with homology to bacterial RNase J Have 5' - to 3'-exoribonuclease activity. J Biol Chem 285: 1757417583.

Commichau FM, Rothe FM, Herzberg C, Wagner E, Hellwig D, Lehnik-Habrink M, Hammer E, Volker U, Stülke J. 2009. Novel activities of glycolytic enzymes in Bacillus subtilis: interactions with essential proteins involved in mRNA processing. Mol Cell Proteomics 8: $1350-1360$.

Condon C. 2003. RNA processing and degradation in Bacillus subtilis. Microbiol Mol Biol Rev 67: 157-174.

Condon C. 2010. What is the role of RNase J in mRNA turnover? RNA Biol 7: 316-321.

Deana A, Celesnik H, Belasco JG. 2008. The bacterial enzyme RppH triggers messenger RNA degradation by $5^{\prime}$ pyrophosphate removal. Nature 451: 355-358.

Deikus G, Condon C, Bechhofer DH. 2008. Role of Bacillus subtilis RNase $\mathrm{J} 1$ endonuclease and $5^{\prime}$-exonuclease activities in trp leader RNA turnover. J Biol Chem 283: 17158-17167.

de la Sierra-Gallay IL, Zig L, Jamalli A, Putzer H. 2008. Structural insights into the dual activity of RNase J. Nat Struct Mol Biol 15: 206-212.

Deutscher MP. 1993. Promiscuous exoribonucleases of Escherichia coli. J Bacteriol 175: 4577-4583.

Even S, Pellegrini O, Zig L, Labas V, Vinh J, Brechemmier-Baey D, Putzer H. 2005. Ribonucleases J1 and J2: two novel endoribonucleases in B. subtilis with functional homology to E. coli RNase E. Nucleic Acids Res 33: 2141-2152.

Evguenieva-Hackenberg E, Walter P, Hochleitner E, Lottspeich F, Klug G. 2003. An exosome-like complex in Sulfolobus solfataricus. EMBO Rep 4: 889-893.

Franzetti B, Sohlberg B, Zaccai G, von Gabain A. 1997. Biochemical and serological evidence for an RNase E-like activity in halophilic Archaea. J Bacteriol 179: 1180-1185.

Hasenöhrl D, Lombo T, Kaberdin V, Londei P, Bläsi U. 2008. Translation initiation factor a/eIF2 $(-\gamma)$ counteracts $5^{\prime}$ to $3^{\prime}$ mRNA decay in the archaeon Sulfolobus solfataricus. Proc Natl Acad Sci 105: 2146-2150.

Kaberdin VR. 2003. Probing the substrate specificity of Escherichia coli RNase E using a novel oligonucleotide-based assay. Nucleic Acids Res 31: 4710-4716.

Kaberdin VR, McDowall KJ. 2003. Expanding the use of zymography by the chemical linkage of small, defined substrates to the gel matrix. Genome Res 13: 1961-1965.

Konrat R. 2009. The protein meta-structure: a novel concept for chemical and molecular biology. Cell Mol Life Sci 66: 3625-3639.
Lehnik-Habrink M, Pfortner H, Rempeters L, Pietack N, Herzberg C, Stülke J. 2010. The RNA degradosome in Bacillus subtilis: identification of CshA as the major RNA helicase in the multiprotein complex. Mol Microbiol 77: 958-971.

Londei P, Altamura S, Cammarano P, Petrucci L. 1986. Differential features of ribosomes and of poly(U)-programmed cell-free systems derived from sulphur-dependent archaebacterial species. Eur J Biochem 157: 455-462.

Mackie GA. 1998. Ribonuclease E is a $5^{\prime}$-end-dependent endonuclease. Nature 395: 720-723.

Madhugiri R, Evguenieva-Hackenberg E. 2009. RNase J is involved in the $5^{\prime}$-end maturation of $16 \mathrm{~S}$ rRNA and $23 \mathrm{~S}$ rRNA in Sinorhizobium meliloti. FEBS Lett 583: 2339-2342.

Mathy N, Benard L, Pellegrini O, Daou R, Wen T, Condon C. 2007. 5'-to-3' exoribonuclease activity in Bacteria: role of RNase J1 in rRNA maturation and 5' stability of mRNA. Cell 129: 681-692.

Mildvan AS, Xia Z, Azurmendi HF, Saraswat V, Legler PM, Massiah MA, Gabelli SB, Bianchet MA, Kang LW, Amzel LM. 2005. Structures and mechanisms of Nudix hydrolases. Arch Biochem Biophys 433: 129-143.

Needleman SB, Wunsch CD. 1970. A general method applicable to the search for similarities in the amino acid sequence of two proteins. J Mol Biol 48: 443-453.

Newbury SF. 2006. Control of mRNA stability in eukaryotes. Biochem Soc Trans 34: 30-34.

Oussenko IA, Abe T, Ujiie H, Muto A, Bechhofer DH. 2005. Participation of $3^{\prime}$-to-5' exoribonucleases in the turnover of Bacillus subtilis mRNA. J Bacteriol 187: 2758-2767.

Pedulla N, Palermo R, Hasenöhrl D, Bläsi U, Cammarano P, Londei P. 2005. The archaeal eIF2 homologue: functional properties of an ancient translation initiation factor. Nucleic Acids Res 33: 18041812.

Portnoy V, Evguenieva-Hackenberg E, Klein F, Walter P, Lorentzen E, Klug G, Schuster G. 2005. RNA polyadenylation in Archaea: not observed in Haloferax while the exosome polynucleotidylates RNA in Sulfolobus. EMBO Rep 6: 1188-1193.

Shahbabian K, Jamalli A, Zig L, Putzer H. 2009. RNase Y, a novel endoribonuclease, initiates riboswitch turnover in Bacillus subtilis. EMBO J 28: 3523-3533.

She Q, Singh RK, Confalonieri F, Zivanovic Y, Allard G, Awayez MJ, Chan-Weiher CC, Clausen IG, Curtis BA, De Moors A, et al. 2001. The complete genome of the crenarchaeon Sulfolobus solfataricus P2. Proc Natl Acad Sci 98: 7835-7840.

Tourriere H, Chebli K, Tazi J. 2002. mRNA degradation machines in eukaryotic cells. Biochimie 84: 821-837.

Wurtzel O, Sapra R, Chen F, Zhu Y, Simmons BA, Sorek R. 2010. A single-base resolution map of an archaeal transcriptome. Genome Res 20: 133-141.

Yao S, Bechhofer DH. 2010. Initiation of decay of Bacillus subtilis rpsO mRNA by endoribonuclease RNase Y. J Bacteriol 192: 32793286. 

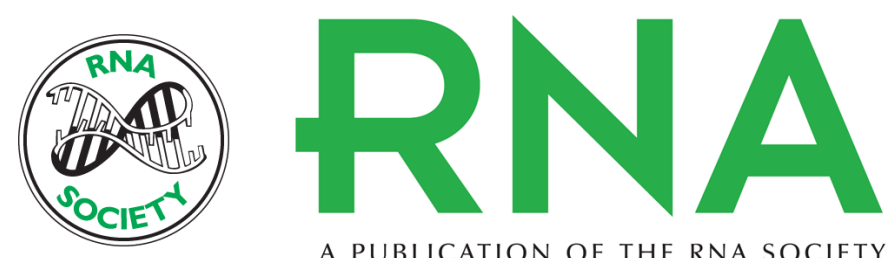

A PUBLICATION OF THE RNA SOCIETY

\section{Identification of an RNase $\mathrm{J}$ ortholog in Sulfolobus solfataricus: Implications for 5 '-to-3' directional decay and 5'-end protection of mRNA in Crenarchaeota}

David Hasenöhrl, Robert Konrat and Udo Bläsi

RNA 2011 17: 99-107 originally published online November 29, 2010

Access the most recent version at doi:10.1261/rna.2418211

Supplemental Material

References

License

Email Alerting Service
http://rnajournal.cshlp.org/content/suppl/2010/11/17/rna.2418211.DC1

This article cites 38 articles, 13 of which can be accessed free at: http://rnajournal.cshlp.org/content/17/1/99.full.html\#ref-list-1

Receive free email alerts when new articles cite this article - sign up in the box at the top right corner of the article or click here.

\section{IIIII!' Providing Precise Solutions for your research.}

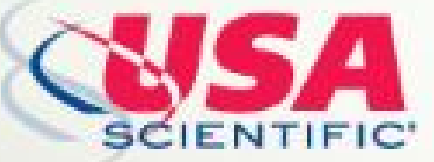

To subscribe to RNA go to:

http://rnajournal.cshlp.org/subscriptions 